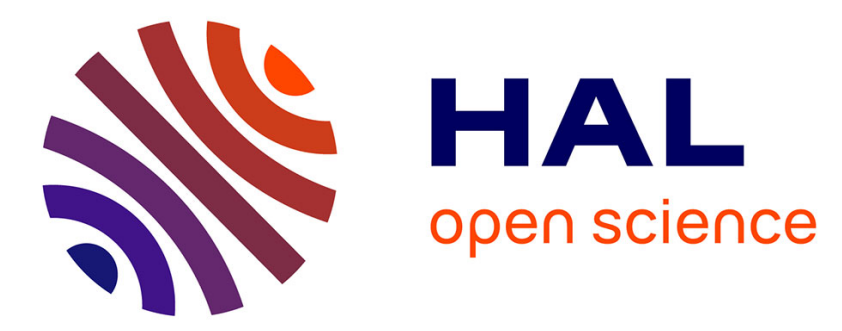

\title{
The Influence of the Formal Replacement of Thiophenes by Stannoles in Terthiophene and Sexithiophene on the Optoelectronic Properties and Electrochemical Behavior
}

Jonas Hoffmann, Isabel-Maria Ramirez y Medina, Muriel Hissler, Anne Staubitz

\section{To cite this version:}

Jonas Hoffmann, Isabel-Maria Ramirez y Medina, Muriel Hissler, Anne Staubitz. The Influence of the Formal Replacement of Thiophenes by Stannoles in Terthiophene and Sexithiophene on the Optoelectronic Properties and Electrochemical Behavior. Dalton Transactions, 2021, 50 (18), pp.62136221. 10.1039/D1DT00565K . hal-03219553

\section{HAL Id: hal-03219553 \\ https://hal.science/hal-03219553}

Submitted on 6 May 2021

HAL is a multi-disciplinary open access archive for the deposit and dissemination of scientific research documents, whether they are published or not. The documents may come from teaching and research institutions in France or abroad, or from public or private research centers.
L'archive ouverte pluridisciplinaire HAL, est destinée au dépôt et à la diffusion de documents scientifiques de niveau recherche, publiés ou non, émanant des établissements d'enseignement et de recherche français ou étrangers, des laboratoires publics ou privés. 


\title{
The Influence of the Formal Replacement of Thiophenes by Stannoles in Terthiophene and Sexithiophene on the Optoelectronic Properties and Electrochemical Behavior
}

\begin{abstract}
Jonas Hoffmann, ${ }^{\mathrm{a}, \mathrm{b}, \mathrm{c}}$ Isabel-Maria Ramirez y Medina, ${ }^{\mathrm{a}, \mathrm{b}}$ Muriel Hissler ${ }^{\mathrm{c},{ }^{*}}$ and Anne Staubitz ${ }^{\mathrm{a}, \mathrm{b},{ }^{*}}$
Polystannoles with thienyl co-monomers are in many ways similar to polythiophenes, but they display much reduced band gaps. However, their polymerization processes are not well researched. Thiophene can be oxidatively electropolymerized, but as stannoles are organometallic, the fundamental question arises whether their inclusion in a conjugated backbone can protect them sufficiently to be able to perform an oxidative electropolymerization. As well-defined oligothiophenes can be used as models to understand the optical and electronic properties of polythiophenes, we transposed this concept on stannole containing polymers; therefore we synthesized a monomeric $\mathbf{1}$ and dimeric thiophene-flanked stannole $\mathbf{2}$ and investigated their optoelectronic properties comparatively including polystannoles and the corresponding oligothiophenes in our analysis. With respect to monomer 1 , a significantly redshifted absorption $\left(\lambda_{\max }=510 \mathrm{~nm}, \Delta=93 \mathrm{~nm}\right)$ and a small optical band gap $\left(E_{g, o p t}(2)=2.13 \mathrm{eV}\right)$, close to the band gap of polymeric stannoles, was observed. In comparison to oligothiophenes, these thienyl-flanked stannoles exhibited a redshift in absorption and emission as well as a lower oxidation potential. Despite these differences, they showed an oligothiophene-like electrochemical behavior. Stannole 1 and the dimer $\mathbf{2}$ were subjected to an electropolymerization process. This process was investigated in detail by spectroelectrochemical methods which showed that radical cation species were formed in situ but readily decomposed. Nevertheless, under the milder multiscan cyclovoltammetric conditions, electropolymerization occurred as shown by cyclovoltammetry.
\end{abstract}

\section{Introduction}

The integration of heteroelements in a cyclopentadiene scaffold facilitates the formation of materials with tunable optoelectronic properties. Besides common heterocyclic structures like thiophenes, pyrroles and furans, ${ }^{1-3}$ more unusual phospholes $^{4-6}$ and siloles ${ }^{7-9}$ have been studied extensively for their application in organic electronics. A heavier group 14 congener of cyclopentadiene is stannole, which contains a tin atom as a replacement for the $\mathrm{sp}^{3}$-carbon atom in cyclopentadiene. Stannoles have been widely used as precursor molecules for boron-containing heterocycles ${ }^{10}, 11$ or as a synthetic tool for accessing polycyclic aromatic hydrocarbons; ${ }^{12}$ but investigations on stannoles themselves as materials for optoelectronic applications remain elusive. ${ }^{13}$ However, most recently, monomeric stannoles were studied regarding their aggregation-induced emission (AIE) behavior. ${ }^{14}$ Due to their $\sigma^{*-}$ $\pi^{*}$-conjugation ${ }^{13}$ (also described in a hyperconjugation model), ${ }^{15,} 16$ the gap between the highest occupied molecular orbital (HOMO) and the lowest unoccupied molecular orbital (LUMO) is narrowed. Therefore, these heterocycles display beneficial physical properties for potential applications in organic electronics. ${ }^{17}$ The manipulation of the stannoles' $\pi$ backbone stannoles is a promising method to fine-tune the

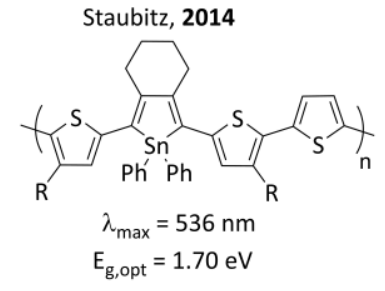

Tomita, 2019

Fig. 1 Polymeric stannoles synthesized and studied by Staubitz ${ }^{18}$ and Tomita. ${ }^{19}$

HOMO-LUMO gap, more so than changing the substituents on the tin atom..$^{20}$ Extending the $\pi$-system by the copolymerization of thienyl-flanked stannoles led to a material with broad lowenergy absorption $\left(\lambda_{\max }=536 \mathrm{~nm}\right)$ in solution and a small optical band gap $\left(E_{g, o p t}=1.70 \mathrm{eV}\right)$ in a thin film (Fig. 1)..$^{18}$ Recently, another stannole based polymer was prepared by the transmetalation of a polymerized bis(dialkoxylphenyl)titanacyclopentadiene with organotin halides. The resulting polymeric material exhibited a broad UV/Vis absorption $\left(\lambda_{\max }=491 \mathrm{~nm}\right)$ in solution and the polymer had a low optical band gap in the film $\left(E_{g, o p t}=1.99 \mathrm{eV}\right) .{ }^{19}$ In all cases, it was shown that by the implementation of tin-atom instead of a sulfur-atom (as in thiophene) a substantial bathochromic shift resulted and the optical band gap of the material narrowed.

Besides accessing stannole polymers with conjugated backbones by catalytic cross-coupling reactions, ${ }^{18}$ or polymer

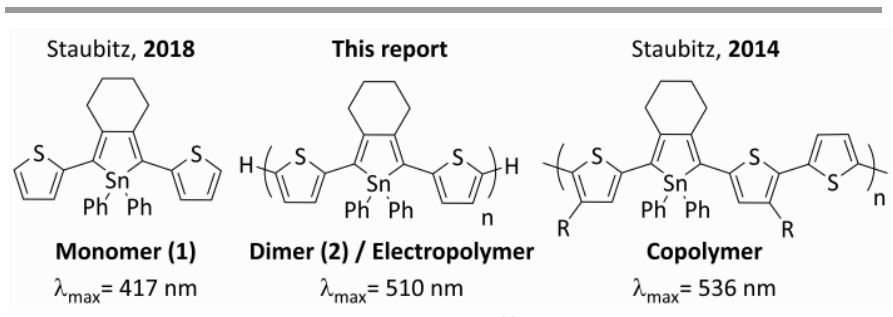

Fig. 2 Structures of thienyl-flanked stannole $1,^{20}$ its dimer 2 and the first stannolecontaining copolymer. ${ }^{18}$ 
a)

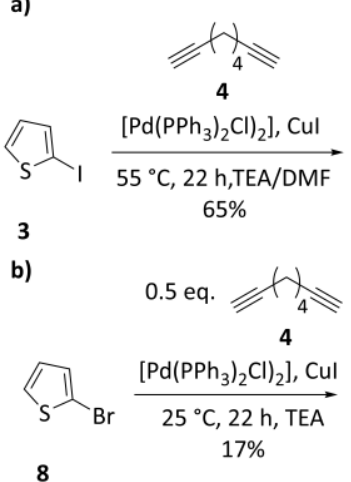

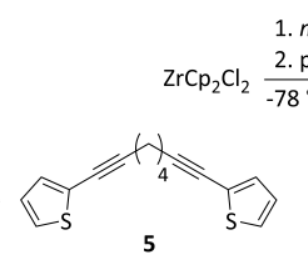

1. nBuLi, BTMSA

$\mathrm{Me}_{3} \mathrm{Si}$ $8^{\circ} \mathrm{C}, 40 \mathrm{~min}, \mathrm{THF}-\mathrm{Cp}_{2} \mathrm{Zr}-\mathrm{SiMe}_{3}$
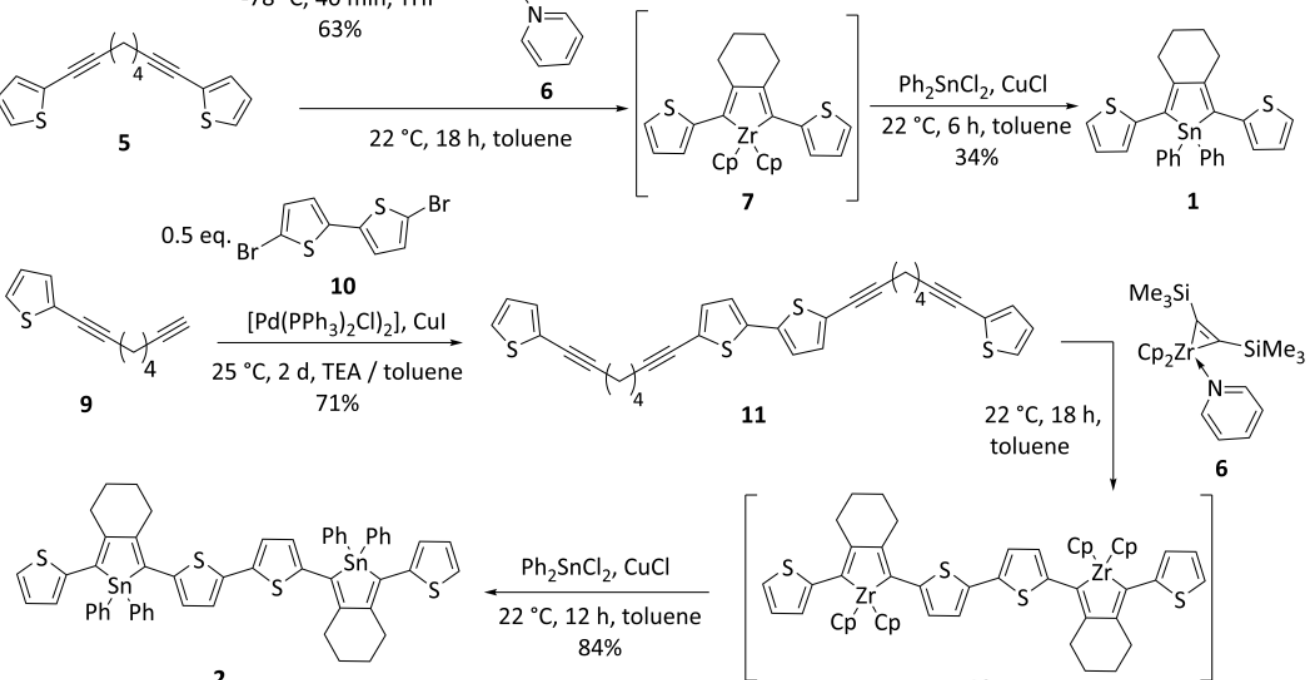

Scheme 1: Synthesis of (a) the stannole derivative $\mathbf{1}^{20}$ and (b) its dimer $\mathbf{2}$. Synthetic details are also found in the supporting information.

analogous reactions, ${ }^{19}$ electropolymerization of redox-active monomers became a powerful method to directly deposit the in situ formed polymers on transparent electrodes. ${ }^{21}$ Especially thienyl, pyrrole and aniline motifs are readily polymerizable under oxidative conditions. ${ }^{22}$ This concept proved also transferable to thienyl-flanked heteroles, e.g. phospholes ${ }^{23,} 24$ and selenophenes, ${ }^{25}$ where the thienyl moieties were oxidatively coupled, but the oxidation-sensitive heterole remained unaffected. ${ }^{24}$ Although most stannoles are stable in air, they are organometallic compounds, which tend to be highly sensitive to oxidation. The reported stannoles were surprisingly stable under cross-coupling conditions (depending on the substitution on Sn), ${ }^{18}$ although conditions can be found in which they do cross-couple, ${ }^{26}$ which includes essentially an oxidation reaction.

To investigate the potential of thienyl-flanked stannoles in electropolymerization processes, stannoles $\mathbf{1}$ and $\mathbf{2}$ were synthesized and their general optoelectronic properties (absorption, emission, redox behavior) were studied (Fig. 2). Moreover, we investigated the stannole's stability in electrochemical processes by spectroelectrochemical experiments.

\section{Results and Discussion}

\section{Synthesis}

In general, both stannoles were obtained after the reductive metalation of thienyl-substituted di-ynes with Rosenthal's zirconocene 27,28 to give zirconacyclopentadienes followed by transmetalation with diphenyltin dichloride. The synthesis of monomeric bis(thienyl)-flanked stannole $\mathbf{1}$, synthesized by this strategy, was reported previously by our group (Scheme 1, ESI). ${ }^{20}$ To access the corresponding dimeric stannole derivative $\mathbf{2}$, a synthetic strategy developed by Tilley and co-workers ${ }^{29}$ was used. A Sonogashira coupling of 2-bromothiophene (8) and octa-1,7-diyne (4) furnished 2-(octa-1,7-diyne)thiophene (9). In an another Sonogashira reaction of 5,5'-dibromo-2,2'bithiophene (10) with two equivalents of $\mathbf{9}$, the precursor 11 was obtained in a good yield of $71 \%$. The alkyne $\mathbf{1 1}$ was then subjected to a reductive intramolecular ring closure with Rosenthal's reagent (6) to provide a zirconacyclopentadiene $\mathbf{1 2}$ intermediate in situ. A subsequent transmetalation reaction with $\mathrm{CuCl}$, followed by a reaction with diphenyltin dichloride furnished the desired stannole $\mathbf{2}$ in a high yield of $84 \%$.

Although 1 was well soluble in aromatic or halogenated solvents, stannole $\mathbf{2}$ exhibited a poor solubility in common solvents (toluene, chloroform, DCM), in which deeply redcolored solutions were obtained. Their chemical identity was proven by ${ }^{1} \mathrm{H},{ }^{13} \mathrm{C}\left\{{ }^{1} \mathrm{H}\right\}$, and ${ }^{119} \mathrm{Sn}\left\{{ }^{1} \mathrm{H}\right\}$ NMR spectroscopy, FTIR spectroscopy and HRMS. The chemical shift of 2 in the ${ }^{119} \mathrm{Sn}\left\{{ }^{1} \mathrm{H}\right\}$ NMR spectrum was found at $\delta=-81.0 \mathrm{ppm}$ and therefore the $\mathrm{Sn}$ atoms were in similar chemical environments as in $\mathbf{1}$ $(\delta=-82.4 \mathrm{ppm})$. Surprisingly, the dissolved stannole derivative 2 showed rapid decomposition after exposition towards ambient light, which was not observed for stannole 1 (See SI, Fig. S15). The decomposition of $\mathbf{2}$ after exposition to sunlight was analyzed by ${ }^{119} \mathrm{Sn}\left\{{ }^{1} \mathrm{H}\right\} \mathrm{NMR}$ analysis where, after $120 \mathrm{~min}$, no signal was detectable anymore. The ${ }^{1} \mathrm{H}$ NMR spectra showed unassignable signals in the aromatic region and a shift of the signals for the cyclohexyl protons to higher field. The latter might indicate that the tin-atom was released from the cyclopentadiene ring and therefore it is suspected that a ringopened structure was formed, as observed for hydrolysis of similar zirconocene structures. ${ }^{27}$ The thermal stability of stannoles $\mathbf{1}$ and $\mathbf{2}$ was investigated by thermogravimetric analysis (TGA). It revealed that both stannoles were thermally stable up to temperatures of $200{ }^{\circ} \mathrm{C}$. Compound $\mathbf{1}$ underwent a continuous loss of mass, whereas stannole $\mathbf{2}$ exhibited a twostep decomposition Their behavior was comparable to their thienyl-analogs ter- and sexithiophene (See SI, Fig. S18). 

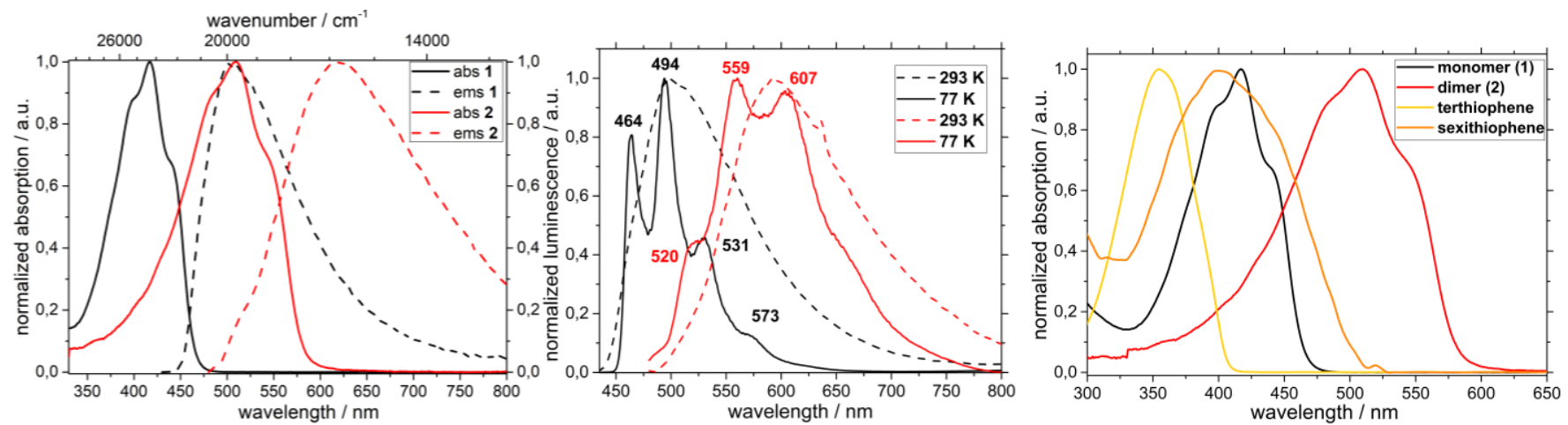

Fig. 3 (left) Absorption (solid line) and luminescence spectra (dashed line) of stannoles $\mathbf{1}$ (black) and $\mathbf{2}$ (red) obtained in DCM. (middle) Luminescence spectra of stannole $\mathbf{1}$ (black) and $\mathbf{2}$ (red) at $293 \mathrm{~K}$ (dashed line) and $77 \mathrm{~K}$ (solid line) measured in 2-methyltetrahydrofuran (10-5 M). (right) Absorption spectra of stannole $\mathbf{1}$, 2, ter- and
sexithiophene in DCM.

\section{Photophysical Characterization}

To estimate the effect of a lateral extension of the conjugated system (both $\pi$-conjugation and $\sigma^{*} \pi^{*}$-conjugation) in stannoles, comparative UV/Vis absorption and luminescence studies were conducted for stannole derivative $\mathbf{1}$ and its dimer 2 (Fig 3, Table 1). Stannole 2 exhibited a bathochromically shifted absorption $\left(\lambda_{\max }=510 \mathrm{~nm}\right.$ ) compared to the absorption of $1\left(\lambda_{\max }=417 \mathrm{~nm}, \Delta(\mathbf{2 - 1})=93 \mathrm{~nm}\right.$, Fig. 3) along with a significantly broadened absorption indicated by the peaks full width at half maximum $(F W M H(2)=113 \mathrm{~nm}$, $\mathrm{FWMH}(\mathbf{1})=75 \mathrm{~nm})$.

As the luminescence properties of stannoles are largely unknown, ${ }^{13}$ we investigated the photoluminescence of stannole $\mathbf{1}$ and $\mathbf{2}$ at ambient and low temperature (Fig. 3, left, Table 1). The luminescence spectrum of stannole 1 showed one emission band centered at $\lambda_{\max }=510 \mathrm{~nm}$ with a large Stokes shift $\left(4450 \mathrm{~cm}^{-1}\right)$, which may indicate strong conformational changes between the ground state of the stannole 1 and its excited state. Stannole $\mathbf{2}$ emitted in the lower-energy region $\left(\lambda_{\max }=620 \mathrm{~nm}\right)$ with a broader band $(\mathrm{FWMH}(2)=189 \mathrm{~nm})$ compared to stannole $\mathbf{1}(\mathrm{FWMH}(\mathbf{1})=114 \mathrm{~nm})$ and with a smaller Stokes shift $\left(3479 \mathrm{~cm}^{-1}\right)$. Stannole derivatives 1 and 2 were only slightly emissive in DCM solutions $\left(\Phi_{\text {lum }}=0.013\right.$ for 1, $\Phi_{\text {lum }}=0.026$ for 2). To obtain more fine-structured luminescence spectra, $\mathbf{1}$ and $\mathbf{2}$ were subjected to lower temperature $(77 \mathrm{~K})$ luminescence spectroscopy in the glassy state (in 2-methyltetrahydrofuran as the matrix) (Fig. 3, middle). At lower temperature, the line broadening contributions of the vibrational modes were reduced and the fine-structure vibronic bands became visible. The emission spectrum of stannole $\mathbf{1}$ was slightly hypsochromically shifted and exhibited distinctly structured bands at $464 \mathrm{~nm}, 494 \mathrm{~nm}$ and $531 \mathrm{~nm}$ and a weak band at $573 \mathrm{~nm}$. The low-temperature luminescence signal of $\mathbf{2}$ was less structured, but still exhibited three distinguishable bands $(520 \mathrm{~nm}, 559 \mathrm{~nm}, 607 \mathrm{~nm})$.

Compared to the room temperature and low-temperature luminescence spectra of ter- and sexithiophene, a bathochromic shift (1 vs. terthiophene: $\Delta=63 \mathrm{~nm}, 2$ vs. sexithiophene $\Delta=74 \mathrm{~nm}$ ), and broader emission spectra were observed. In both $\mathbf{1}$ and $\mathbf{2}$, the Stokes shifts were larger than in ter- and sexithiophene, but decreased luminescence quantum yields were observed for the stannoles $\mathbf{1}$ and $\mathbf{2}$ (Table 1). ${ }^{30}$ The latter observation can be assigned to the heavy atom effect of the tin allowing more non-emissive pathways for thermal relaxation. ${ }^{13}$ In contrast to their thienyl-analogs ter- and sexithiophene, the thienyl-substituted stannoles exhibited redshifted and broader absorption bands as indicated by $\lambda_{\text {max,abs }}$ and the FWMH values (Fig. 3, right, Table 1).

Moreover, to compare the effect of a lateral extension of oligothiophenes and stannole/thiophene derivatives, their optical HOMO-LUMO gap was considered. The optical HOMOLUMO gap of stannole $1\left(E_{g, o p t}=2.66 \mathrm{eV}\right)$, its dimer 2 $\left(E_{g, o p t}=2.13 \mathrm{eV}\right)$ and the thiophene-stannole copolymer $\left(E_{g, o p t}=1.91 \mathrm{eV}^{18}\right)$ were essentially lower than for respective oligothiophenes, terthiophene $\left(E_{\mathrm{g}, \mathrm{opt}}=3.04 \mathrm{eV}\right)^{30}$, sexithiophene $\left(E_{\mathrm{g}, \mathrm{opt}}=2.46 \mathrm{eV}\right)^{30}$ and poly $(3-n h e x y / t h i o p h e n-$ 2,5 -diyl) $\left(E_{\mathrm{g}, \mathrm{opt}}=2.22 \mathrm{eV}\right)^{31}$. The trend of extending the chain length of the oligomers in conductive polymers is best described by plotting the $E_{g, o p t}$ versus the inverse of the chain length which

Table 1 Overview of absorption and emission properties of stannole derivatives $\mathbf{1}$ and $\mathbf{2}$. Fig. $\mathbf{4}$ Photographs of solutions of $\mathbf{1}$ and $\mathbf{2}$ in DCM under ambient light and irradiated at $365 \mathrm{~nm}$.

\begin{tabular}{|c|c|c|c|c|c|c|c|c|}
\hline & $\begin{array}{c}\lambda_{\text {abs,max }} \\
n m\end{array}$ & FWMH $/ \mathrm{nm}$ & $\lg (\varepsilon)$ & $\lambda_{\text {onset }^{[\mathrm{b}]}} / \mathrm{nm}$ & $\lambda_{\text {em,max }}{ }^{[\mathrm{a}]} / \mathrm{nm}$ & FWHM $/ \mathrm{nm}$ & Stokes shift $/ \mathrm{cm}^{-1}$ & $\Phi_{\text {lum }}$ \\
\hline $\mathbf{1}$ & 417 & 75 & 4.32 & 466 & 512 & 114 & 4450 \\
\hline $\mathbf{2}$ & 510 & 113 & 4.71 & 582 & 620 & 189 & $0.013^{[\mathrm{c}]}$ \\
\hline Terthiophene & $354^{[\mathrm{e}]}$ & $62^{[\mathrm{f}]}$ & $4.34^{[\mathrm{e}]}$ & $408^{[\mathrm{f}]}$ & $407^{[\mathrm{e}]}$ & $58^{[\mathrm{f}]}$ & 3479 & $0.026^{[\mathrm{d}]}$ \\
\hline Sexithiophene & $436^{[\mathrm{e}]}$ & $85^{[\mathrm{f}]}$ & $4.68^{[\mathrm{e}]}$ & $504^{[\mathrm{f}]}$ & $502^{[\mathrm{e}]}$ & $86^{[\mathrm{f}]}$ & $3019^{[\mathrm{f}]}$ & $0.066^{[\mathrm{e}]}$ \\
\hline
\end{tabular}

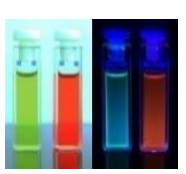

${ }^{\text {[a] }}$ Measured in DCM solutions (approx. $10^{-5}-10^{-6} \mathrm{M}$.) ${ }^{[b]}$ Calculated from the offset wavelength derived from the lowest energy absorption band. ${ }^{[c]}$ Measured against quinine sulfate in $0.1 \mathrm{M} \mathrm{H}_{2} \mathrm{SO}_{4}$ in water. [d] Measured against fluorescein in $0.1 \mathrm{M} \mathrm{NaOH}$ in water. ${ }^{[\mathrm{e}]}$ Measured in dioxane. ${ }^{30}$ [f] Based on data derived from literature. ${ }^{30}$ 

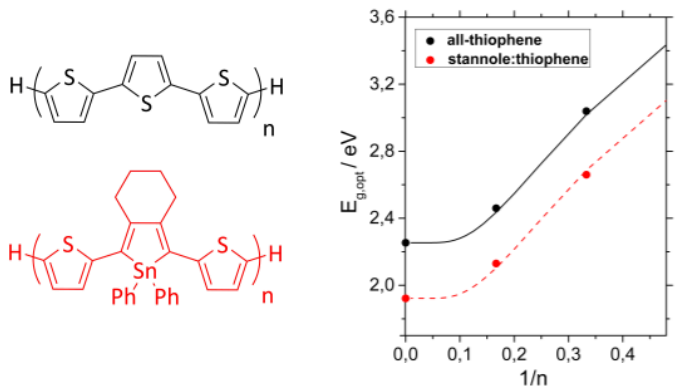

Fig. 5 Plot of $E_{g, o p t}$ of oligothiophenes and thienyl-substituted stannoles against $1 / n$. As polymers, stannole copolymer ${ }^{18}$ and $\mathrm{P}_{3} \mathrm{HT}^{31}$ were chosen. The fit function has been described elsewhere. ${ }^{32}$

gives the effective conjugation length (Fig. 5). ${ }^{32}$ Although there are only three points for the pure oligo- or polythiophene and corresponding stannoles, these materials revealed a similar, but parallelly shifted, relation of the chain length and the optical HOMO-LUMO gap highlighting the similarity of the allthiophene and the stannole/thiophene-based oligomers. It can clearly be seen that the stannole has a strong effect on lowering the energy gap of excitation.

\section{Electrochemistry}

Since absorption spectroscopy already indicated that the HOMO-LUMO gap was significantly narrowed going from stannole $\mathbf{1}$ to its dimer $\mathbf{2}$, we investigated the electrochemical properties of both via cyclic voltammetry (Fig. 6, Table 2). The cyclic voltammogram of $\mathbf{1}$ has been reported exhibiting a nonreversible oxidation process, ${ }^{20}$ whereas dimer $\mathbf{2}$ had two reversible oxidation waves at lower potential $\left(E_{1 / 2}{ }^{0 \times 1}=0.51 \mathrm{~V}\right.$ $\mathrm{E}_{1 / 2}{ }^{\mathrm{O} \times 2}=0.70 \mathrm{~V}, \Delta=0.19 \mathrm{~V}$ ), which were reversible after the third scan. However, the appearance of a two-electron process for $\mathbf{2}$ indicated the occurrence of a di-cationic $\mathbf{2}^{2+}$ species. Strikingly, the electrochemical behavior of bis-thienyl-flanked

Table 2: Overview of electrochemical data and HOMO/LUMO levels of $\mathbf{1}$ and $\mathbf{2}$

\begin{tabular}{|c|c|c|c|}
\hline & $\mathrm{E}_{\mathrm{O} \times 1} / \mathrm{V}$ & $\mathrm{E}_{\mathrm{O} \times 2} / \mathrm{V}$ & $\Delta / \mathrm{V}$ \\
\hline $\mathbf{1}$ & +0.89 & - & - \\
\hline $\mathbf{2}$ & $+0.51^{\mathrm{a}}$ & $+0.70^{\mathrm{a}}$ & 0.19 \\
\hline Terthiophene & +1.05 & & \\
\hline Sexithiophene & $+0.84^{\mathrm{a}}$ & $+1.05^{\mathrm{a}}$ & 0.21 \\
\hline
\end{tabular}

All values were referenced against saturated calomel electrode. Values for ter- and sexithiophene were adapted from literature. ${ }^{33}$ a Reversible oxidation processes.
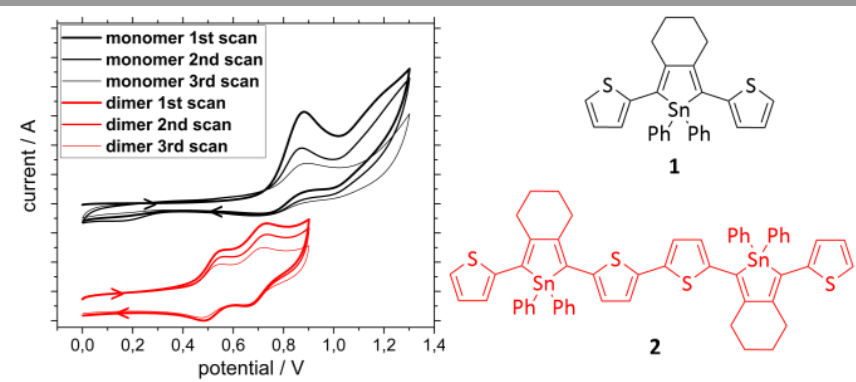

Fig. 6 Cyclic voltammogram of stannole $\mathbf{1}$ (black) and $\mathbf{2}$ (red) in DCM with $n \mathrm{Bu}_{4} \mathrm{NPF}_{6}$ as conducting salt using platinum working electrodes.

stannoles $\mathbf{1}$ and $\mathbf{2}$ were similar to their all-thienyl analogs terand sexithiophene: the electrochemical oxidation of terthiophene showed one irreversible oxidation wave ( $E_{\mathrm{Ox} \text { I }}$ $=1.05 \mathrm{~V}$ ), whereas sexithiophene exhibited two reversible oxidation signals $\left(\mathrm{E}_{1 / 2}{ }^{\mathrm{O} \times 1}=0.84 \mathrm{~V}, \mathrm{E}_{1 / 2}{ }^{\mathrm{O} \times 2}=1.05 \mathrm{~V}, \Delta=0.21 \mathrm{~V}\right) .^{33}$ Therefore, the conclusion could be drawn that the implementation of stannole heterocycles in thienyl-systems does not drastically affect the overall electrochemical behavior. From the electrochemical analysis and the $\lambda_{\text {onset, }}$ the resulting HOMO and LUMO levels of $\mathbf{1}$ and $\mathbf{2}$ were estimated: ${ }^{34}$ It was revealed that the extension of the conjugated system from 1 $\left(\mathrm{E}_{\text {Hомо }}=-5.12 \mathrm{eV}, \mathrm{E}_{\mathrm{LUMO}}=-2.46 \mathrm{eV}\right)$ to the dimer 2 increased the HOMO $\left(\mathrm{E}_{\text {Hомо }}=-4.85 \mathrm{eV}\right)$ but stabilized the LUMO $\left(\mathrm{E}_{\mathrm{LUMO}}=-\right.$ $2.72 \mathrm{eV}$ ). Overall, the electronic HOMO/LUMO gap was reduced from $2.66 \mathrm{eV}$ to $2.13 \mathrm{eV}$. Stannole 1 presented a non-reversible oxidation process indicating that compound $\mathbf{1}$ is involved in a chemical transformation being likely an electropolymerization as observed for terthiophene. ${ }^{33}$

\section{Electropolymerization}

Since stannole 1 was reactive upon electrochemical oxidation in the $\mathrm{CV}$ setup, it was subjected to a multiscan cyclic voltammetry to investigate an electropolymerization process. In general, electropolymerization is a rapid process, which is driven by kinetics and proceeds in milder conditions than electrochemical oxidation in spectroelectrochemical setups. Therefore, the electroactive species is barely exposed to higher current densities, and thus decomposing/oxidation can often be minimized as seen for the electropolymerization of phospholes.23, 24 The formation of polymers from thienylflanked stannoles 1 was conducted by multi-scan electrochemical oxidation between $0.0 \mathrm{~V}$ and $1.3 \mathrm{~V}$ in $\mathrm{DCM} / n$ pentane on a platinum disk electrode with a sweep rate of $200 \mathrm{mV} / \mathrm{s}$ (Fig. 7, left). Upon increasing the number of scans, the signals at $0.91 \mathrm{~V}$ and at $0.67 \mathrm{~V}$ grew over time. After 50 cycles, a reddish film on the electrode was formed which was insoluble in organic solvents; the shape of the electrochemical response remained constant after these 50 cycles. The modified electrodes were rinsed with DCM characterized by a final CV measurement in monomer-free DCM solution containing $0.2 \mathrm{M}$ $\mathrm{Bu}_{4} \mathrm{NPF}_{6}$ at a scan rate of $200 \mathrm{mV} / \mathrm{s}$ (Fig. 7, right). The polymer
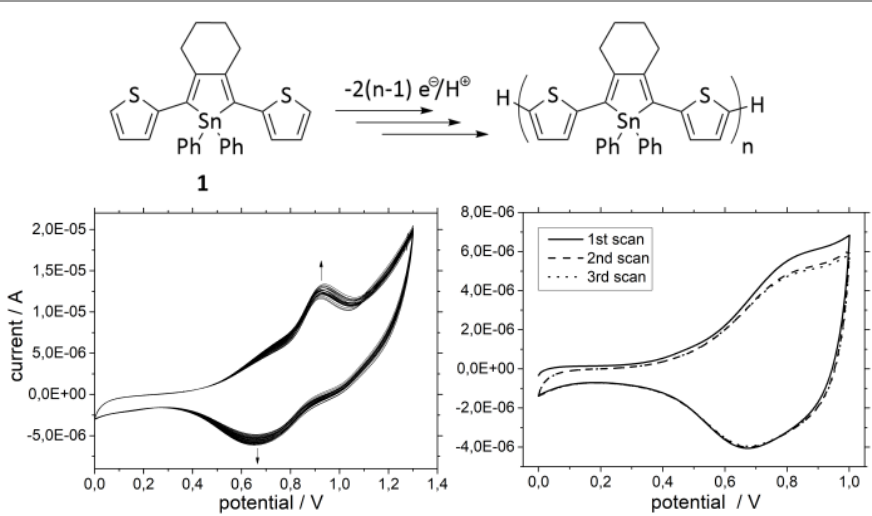

Fig. 7 Multi-scan voltammogram of 1 (left) in DCM/ $n$-pentane (1/1) with $n \mathrm{Bu}_{4} \mathrm{NPF}_{6}$ as conducting salt and a sweep rate of $200 \mathrm{mV} / \mathrm{s}$ on a platinum electrode. After washing the electrode with DCM, a voltammogram (right) in a monomer-free $\mathrm{DCM} / n$-pentane $(1 / 1)$ solution with $n \mathrm{Bu}_{4} \mathrm{NPF}_{6}$ was conducted. 


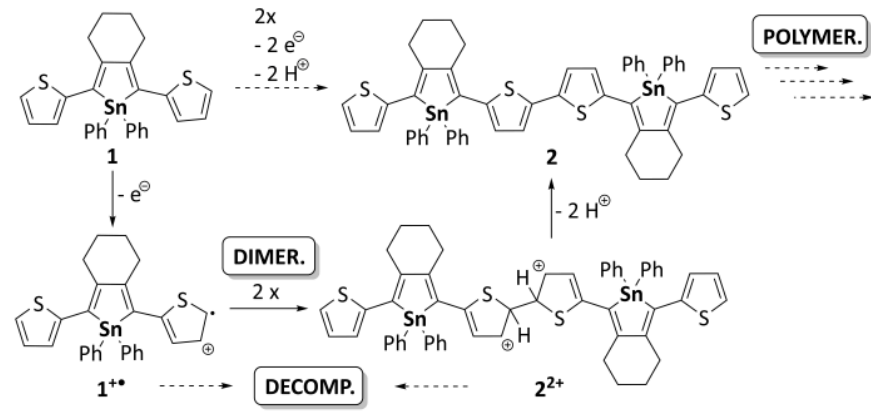

Scheme 2 Proposed mechanism of an oxidative polymerization of thienyl-substituted 1 including the formation of stannole radical cation $\mathbf{1}^{+*}$, dimer dication $\mathbf{2}^{2+}$ and the dimer 2. The decomposition of the stannole species could also occur as side-reaction.

film was stable under these conditions and the scans are largely identical. In addition, the dimer $\mathbf{2}$ was also subjected to a multiscan electrochemical oxidation (Fig. 8). As the film on the electrode was transferred into a monomer-free solution, the shape of the CV curve was similar to the one obtained by the electropolymerization of monomer $\mathbf{1}$. However, if the multiscan experiments of $\mathbf{1}$ and $\mathbf{2}$ were conducted on a transparent fluorine-doped tin oxide (FTO) no stannole polymer could be obtained. The transfer of this procedure to electrodes that are suitable for scanning-electron microscope surface and energydispersive X-ray spectroscopy analysis (SEM/EDX), e.g. platinum sheet, revealed the absence of any tin in the deposited film. The release of tin might indicate decomposition processes after or during the electropolymerization process.

\section{Spectroelectrochemistry}

In similarity to the mechanism of forming oligothiophenes by

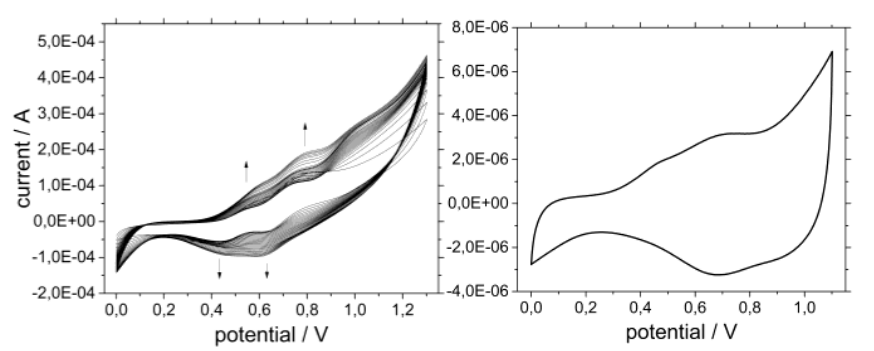

Fig. 8 Multi-scan voltammogram of 2 (left) in $\mathrm{DCM}$ with $n \mathrm{Bu}_{4} \mathrm{NPF}_{6}$ as conducting salt and a sweep rate of $200 \mathrm{mV} / \mathrm{s}$ on a platinum electrode. After washing the electrode with DCM a voltammogram (right) in a monomer-free DCM solution with $n \mathrm{Bu}_{4} \mathrm{NPF}_{6}$ was conducted. electropolymerization, ${ }^{35}$ a mechanism for the thienyl-flanked stannole $\mathbf{1}$ is proposed (Scheme 2). The intermediary stannole species $\left(\mathbf{1}^{+\cdot}, \mathbf{2}^{\mathbf{2 +}}\right)$ require intrinsic stability for an electropolymerization process. To verify the stability of the involved stannole species, the stannoles $\mathbf{1}$ and $\mathbf{2}$ were subjected to a UV/Vis-NIR spectroelectrochemical analysis. This is a versatile method to investigate the effect of the oxidation on the molecular structure based on the combination of absorption spectroscopy and in situ oxidation. It needs pointing out that the described spectroelectrochemical experiments are quasi-static since the diffusion in the cell is limited and the electrode potential is changed incrementally. Therefore, the experiments are not fully analogous to the processes which occur in multi-scan experiments, but they are a good approximation. Stannole 1 was subjected to spectrochemical analysis and the non-reversible oxidation process, as it was determined by cyclic voltammetry, was investigated (Fig. 9, left). The absorption spectra were unaffected until a voltage of $0.8 \mathrm{~V}$ was applied and novel species $(639 \mathrm{~nm}, 700-1000 \mathrm{~nm})$ occurred, which disappeared again over time. Simultaneously, the significant peak $(417 \mathrm{~nm})$ for stannole 1 decreased over time. The arising bands could be due to the absorption of the intermediate doped $\mathbf{1}^{+\cdot}$ species. This observation was confirmed by a similar study on 2,5-di(2-methoxythienyl)-stannole (13)20. This compound is chemically unable to undergo oxidative oligomerization, because the reactive sites are blocked by methoxy groups. Upon oxidation, the formation of a novel species $(686 \mathrm{~nm}, 919 \mathrm{~nm})$, presumably $\mathbf{1 3}^{\mathbf{+}^{-}}$species, was detected while at the same time the absorption signal of the stannole $(438 \mathrm{~nm})$ itself decreased rapidly (Fig. 9, middle). In comparison to stannole $\mathbf{1}$, the same set of absorption signals was found with the only difference that all signals were redshifted due to the methoxy-substituents. ${ }^{20}$ In these two cases, the formation of the radical is observed but a novel band $(314 \mathrm{~nm} / 346 \mathrm{~nm})$ appeared with time (after $2 \mathrm{~min}$ ) and the absorption bands above $600 \mathrm{~nm}$ vanished. This was assigned to the decomposition of the stannole radical cation $\mathbf{1}^{+\cdot}$, based on the absorption spectrum of a previously observed ring-opened butadiene form $\left(\lambda_{\text {abs, } \max }=334 \mathrm{~nm}\right)$, in which tin was absent. ${ }^{27,36}$ A relation to terthiophene and the absorption of the terthiophene radical cation $(780 \mathrm{~nm}, 1480 \mathrm{~nm})^{33}$ was not found.
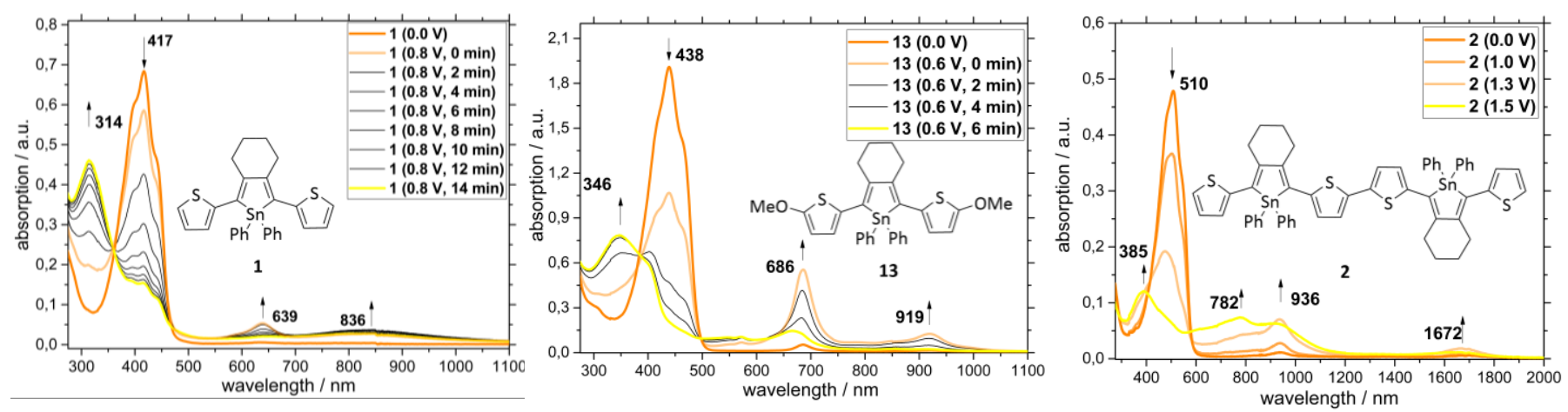

Fig. 9 (Left) Stacked absorption spectra of stannole 1 in DCM with $n \mathrm{Bu}_{4} \mathrm{NPF}_{6}$ as conducting salt upon oxidation starting from $0.80 \mathrm{~V}$ and recording a spectrum every 2 min. (Middle) Stacked absorption spectra of $\mathbf{1 3}$ in DCM with $n B_{4} \mathrm{NPF}_{6}$ as conducting salt upon oxidation. (Right) Stacked absorption spectra of stannole $\mathbf{2}$ in DCM with $n \mathrm{Bu}_{4} \mathrm{NPF}_{6}$ as conducting salt upon oxidation. As 2 decomposed immediately upon oxidation, the voltage was increased gradually (every 2 min) to generate dope species. In all cases the concentration was $10^{-4} \mathrm{M}$. 
The spectroelectrochemical investigation of oligomer $\mathbf{2}$ was also performed (Fig. 9, right). Compound $\mathbf{2}$ underwent electrochemical oxidation even at lower potential, which is consistent with the cyclovoltammetric results, but simultaneously, it showed an indication of decomposition. To generate a better visible signal for the doped species, it was generated at a higher initial voltage $(>1.0 \mathrm{~V})$, while accepting faster decomposition under these conditions. A fast decline of the 2 absorption band $(510 \mathrm{~nm}$ ) was observed; however, new absorption bands in the NIR region (936 nm, $1672 \mathrm{~nm}$ ) appeared. However, none of them were in accordance with the species we observed in the oxidation of $\mathbf{1}$ (Fig. 9, left). Therefore an oligomerization in the spectroelectrochemical oxidation of 1 appeared implausible. The simultaneous increase of the signals at $936 \mathrm{~nm}$ and $1672 \mathrm{~nm}$ indicated the formation of a $\mathbf{2}^{+\cdot}$ species. Also, in this case, the analogy of $\mathbf{2}$ and sexithiophene exists: Chemical oxidation of sexithiophene resulted in the formation of absorption bands at $780 \mathrm{~nm}$ and $1480 \mathrm{~nm}$, which were both assigned to the sexithiophene ${ }^{+\cdot}$ intermediate. ${ }^{33}$ As this is relatively close to the bands observed for the oxidation of $\mathbf{2}$, a formation of $\mathbf{2}^{+\cdot}$ can be assumed.

Due to the analogy of the experimental observation to thiophene analogs, we conclude that our results indicate the formation of stannole radical cation species. Attempts to reduce the radical cation species to the neutral stannoles remained unsuccessful.

\section{Conclusions}

We report the synthesis of the dimer of a bis(thienyl)stannole and the investigation of its optoelectronic and thermal properties as well as those for the corresponding monomer 1. In comparison to $\mathbf{1}$, the novel photolabile stannole $\mathbf{2}$ appeared red-shifted in solution $\left(\lambda_{\max }=512 \mathrm{~nm},\right)$ and significant peak broadening was found. The narrowed HOMO-LUMO gap was also proven by electrochemical analysis and a reversible twoelectron process was found for $\mathbf{2}$ while a non-reversible oxidation was found for $\mathbf{1}$. As this behavior was found for terand sexithiophene, a certain similarity between all-thiophene oligomers terthiophene/sexithiophene and their stannole analogs $\mathbf{1}$ and $\mathbf{2}$ emerged. In comparison to the thienyloligomers, the absorption and luminescence of stannoles $\mathbf{1}$ and $\mathbf{2}$ were shifted bathochromically and exhibited significant line broadening with low luminescence quantum yields. In agreement with the narrowed HOMO/LUMO gaps, the oxidation occurred at lower potentials for $\mathbf{1}$ and $\mathbf{2}$ compared to their thienyl-analogs. In analogy to the electropolymerization of oligothiophenes, stannole $\mathbf{1}$ was subjected to multiscan electrochemical oxidation. Initially, a modified electrode was obtained, which exhibited a specific redox response. As it could not be clarified if the tin was retained in the generated film, further spectroelectrochemical analysis of stannoles 1, 2 and the methoxy-substituted stannole $\mathbf{1 3}$ were conducted to investigate the polymerization process in detail. Additionally, intermediary radical cationic species were observed with absorption ranging into the NIR region for all stannoles although they then readily decomposed.
It appears that the higher degree of delocalization in $\mathbf{2}$ allows easier formation of stable cation radical species (i. e. at lower potential) than in $\mathbf{1}$.

Finally, we conclude that electropolymerization of thienylflanked stannoles is possible, but a delicate process because decomposition of the stannole moiety can occur.

\section{Conflicts of Interest}

There are no conflicts to declare.

\section{Acknowledgements}

J.H. acknowledges funding for a Short Term Scientific Mission from the COST action COST 1302: "European Network on Smart Inorganic Polymers". This work is supported by the Ministère de la Recherche et de l'Enseignement Superieur, the CNRS, the Region Bretagne, and COST CM 1302 (SIPS).

\section{Experimental Section}

\section{General Methods}

All NMR-tubes and glassware were dried in an oven at $200{ }^{\circ} \mathrm{C}$ for $14 \mathrm{~h}$ before use. If not stated otherwise, all reaction vessels were heated to a minimum of $200{ }^{\circ} \mathrm{C}$ under vacuum $\left(1.3 \times 10^{-2}\right.$ mbar to $\left.6.2 \times 10^{-2} \mathrm{mbar}\right)$ and purged with nitrogen or argon at least three times before adding reagents. Syringes were purged with nitrogen or argon three times prior to use. In general, a nitrogen filled glovebox from Inert, Innovative Technology, Inc. Company (<0 0.1 ppm $\mathrm{O}_{2}$ and $<0.1$ ppm $\mathrm{H}_{2} \mathrm{O}$ ) was used unless noted otherwise. All dry solvents were obtained from the solvent purification system (SPS), degassed by three freeze-pump-thaw cycles and stored under a nitrogen atmosphere unless noted otherwise. Kugelrohr distillation was performed with a Büchi B-585 Kugelrohr oven.

\section{Analysis}

All NMR spectra were carried out at $23{ }^{\circ} \mathrm{C} .{ }^{1} \mathrm{H}$ NMR $(600 \mathrm{MHz})$ and ${ }^{13} \mathrm{C}\left\{{ }^{1} \mathrm{H}\right\} \mathrm{NMR}(150 \mathrm{MHz})$ spectra were recorded on a Bruker Avance Neo spectrometer equipped with a TXI probe head or a Bruker DRX $500 \quad\left({ }^{1} \mathrm{H} N M R \quad(500 \mathrm{MHz})\right.$ and ${ }^{13} \mathrm{C}\left\{{ }^{1} \mathrm{H}\right\} \quad \mathrm{NMR}$ (126 MHz)). ${ }^{119} \mathrm{Sn}\left\{{ }^{1} \mathrm{H}\right\} \mathrm{NMR}(223 \mathrm{MHz})$ spectra were recorded on a Bruker Avance Neo spectrometer equipped with a BBO probe head or a Bruker DRX 500 (186 MHz). The ${ }^{119} \mathrm{Sn}\left\{{ }^{1} \mathrm{H}\right\}$ NMR spectra were referenced externally against tetramethylsilane in $\mathrm{CDCl}_{3}$. Where possible, NMR signals were assigned using ${ }^{1} \mathrm{HCOSY}$, ${ }^{1} \mathrm{H} /{ }^{1} \mathrm{H}$ NOESY, ${ }^{1} \mathrm{H} /{ }^{13} \mathrm{C}\left\{{ }^{1} \mathrm{H}\right\} \mathrm{HSOC}$ and ${ }^{1} \mathrm{H} /{ }^{13} \mathrm{C}\left\{{ }^{1} \mathrm{H}\right\} \mathrm{HMBC}$ experiments. As $\mathrm{NMR}$ solvent $\mathrm{CDCl}_{3}$ (Deutero, 99.9\%, stored over alumina) or $\mathrm{C}_{6} \mathrm{D}_{6}$ (Deutero, $99.9 \%$, stored over molecular sieves) was used.

IR spectra were recorded on a Nicolet Thermo iS10 scientific spectrometer with a diamond ATR unit. Electron impact (EI) mass experiments were measured using the direct inlet or indirect inlet methods, with a source temperature of $200{ }^{\circ} \mathrm{C}$ on a MAT95 XL double-focusing mass spectrometer from Finnigan MAT. The ionization energy of the electron impact ionization was $70 \mathrm{eV}$. Atmospheric pressure chemical ionization (APCI) 
experiments were performed on a Bruker Impact II from Bruker Daltonics. The electrochemical studies were carried out under argon using an Eco Chemie Autolab PGSTAT 30 potentiostat for cyclic voltammetry. The following three-electrode configuration was used: the working electrode was a platinum disk, the reference electrode was a saturated calomel electrode and the counter-electrode a platinum wire. All potentials were internally referenced to the ferrocene/ ferrocenium couple. For the measurements, concentrations of $10^{-3} \mathrm{M}$ of the electroactive species were used in a $0.2 \mathrm{M}$ solution of tetrabutylammonium hexafluorophosphate (Sigma Aldrich, $>99 \%$ ) in degassed DCM. The scanning rate was $200 \mathrm{mV} / \mathrm{s}$. For thermal analysis, a Mettler Toledo a DSC/TGA 3+ was used. Melting points were measured on a Büchi M-5600 Melting Point apparatus. UV/Vis spectra were recorded on a Perkin Elmer Lambda 14 spectrometer at $20^{\circ} \mathrm{C}$ using a quartz cuvette with a length of $1 \mathrm{~cm}$. The UV-Vis emission spectra measurements were recorded on a FL 920 Edinburgh Instrument and corrected for the response of the photomultiplier. Quantum yields were calculated relative to quinine sulfate $\left(\left(\Phi=0.54\right.\right.$ in $\left.0.1 \mathrm{M} \mathrm{H}_{2} \mathrm{SO}_{4}\right)$ and fluorescein $(\Phi=0.91$ in $0.1 \mathrm{M} \mathrm{NaOH})$. The low-temperature measurements were performed with a combination of a Dewar and EPR tubes in 2-methyltetrahydrofuran as a solvent. Spectroelectrochemical experiments were performed in DCM with $n \mathrm{Bu}_{4} \mathrm{NPF}_{6}$ as conductive salt $(0.2 \mathrm{M})$. As UV/NIR spectrometer a Jasco V-770 was used. As cell, an Omni Cell Spec with a Pt grid as the working electrode, a Pt wire as the counter electrode and SCE reference electrode was used. Furthermore, a Princeton applied Research Model 362 Scanning Potentiostat was used to apply the voltage given.

The synthesis and analysis of all precursors and $\mathbf{1}$ are found in the supporting information.

Synthesis of the stannole dimer (2)

In a glovebox, 5,5'-bis(8-(thiophen-2-yl)octa-1,7-diyn-1-yl)-2,2'bithiophene $(\mathbf{1 1}, 200 \mathrm{mg}, 371 \mu \mathrm{mol})$ and Rosenthal's zirconocene $(6,349 \mathrm{mg}, 742 \mu \mathrm{mol})$ were dissolved in toluene $(8 \mathrm{~mL})$ and the dark red solution was stirred for $18 \mathrm{~h}$ at $22^{\circ} \mathrm{C}$ under a nitrogen atmosphere. Subsequently, diphenyltin dichloride $(255 \mathrm{mg}, 742 \mu \mathrm{mol})$, copper(I)chloride $(7.3 \mathrm{mg}$, $74 \mu \mathrm{mol})$ and toluene $(2 \mathrm{~mL})$ were added to the solution in a glovebox. The reaction mixture was stirred at $22{ }^{\circ} \mathrm{C}$ for further $12 \mathrm{~h}$. The mixture was quenched under ambient atmosphere with methanol $(100 \mathrm{~mL})$ and the precipitate was collected by centrifugation. In the dark, the precipitate was washed by Soxhlet extraction with methanol and $n$-hexane. The precipitate in the Soxhlet filter was identified as pure product, which was extracted with DCM. After removal of the solvent, the product was obtained as a red powder (2, $338 \mathrm{mg}, 311 \mu \mathrm{mol}, 84 \%)$. The product was sensitive to light.

${ }^{1} \mathrm{H}$ NMR $\left(600 \mathrm{MHz}, \mathrm{CDCl}_{3}\right): \delta=7.68-7.59\left(\mathrm{~m},{ }^{3} \mathrm{~J}_{\mathrm{SnH}}=24.1\right.$, $21.4 \mathrm{~Hz}, 8 \mathrm{H}, \mathrm{Ph}-\mathrm{H}-2,6), 7.41-7.34(\mathrm{~m}, 12 \mathrm{H}, \mathrm{Ph}-\mathrm{H}-3,4,5), 7.27-$ 7.25 (m, 2H, Tph- $H-5), 7.03-6.99$ (m, 2H, Tph- $H-3), 6.99-6.93$ (m, 4H, biTph-H-3,4), $6.86-6.83$ (m, 2H, Tph-H-4), $2.94-2.87$ $\left(\mathrm{m}, 8 \mathrm{H}, \mathrm{CH}_{2}-\mathrm{CH}_{2}\right), 1.85-1.82\left(\mathrm{~m}, 8 \mathrm{H}, \mathrm{CH}_{2}-\mathrm{CH}_{2}\right)$ ppm. ${ }^{13} \mathrm{C}\left\{{ }^{1} \mathrm{H}\right\}$ NMR $\left(151 \mathrm{MHz}, \quad \mathrm{CDCl}_{3}\right): \quad \delta=149.9 \quad$ (stannole-C-4), 149.5 (stannole-C-3), 145.9 (Tph-C-2), 144.6 (biTph-C-5), $138.2\left({ }^{1} J_{\text {SnC }}=\right.$ $248.4 \mathrm{~Hz}, \mathrm{Ph}-\mathrm{C}-1), 138.2$ (biTph-C-2), $137.4\left({ }^{2} J_{\mathrm{SnC}}=22.3 \mathrm{~Hz}, \mathrm{Ph}-\right.$ C-2,6), 131.0 (Tph-C-4), 130.6 (stannole-C-5), 130.5 (stannole-C-
2), $129.6\left({ }^{4} J_{\mathrm{SnC}}=6.5 \mathrm{~Hz}, \mathrm{Ph}-\mathrm{C}-4\right), 129.4(\mathrm{biTph}-\mathrm{C}-3), 129.1\left({ }^{3} J_{\mathrm{SnC}}=\right.$ $27.6 \mathrm{~Hz}$, Ph-C-3,5), 127.2 (biTph-C-4), 126.0 (Tph-C-5), 123.2 (Tph-C-3), $32.1\left(\mathrm{CH}_{2}-\mathrm{CH}_{2}\right), 31.0\left(\mathrm{CH}_{2}-\mathrm{CH}_{2}\right), 23.4\left(\mathrm{CH}_{2}-\mathrm{CH}_{2}\right), 23.4$ $\left(\mathrm{CH}_{2}-\mathrm{CH}_{2}\right)$ ppm. ${ }^{119} \mathrm{Sn}\left\{{ }^{1} \mathrm{H}\right\} \mathrm{NMR}\left(224 \mathrm{MHz}, \mathrm{CDCl}_{3}\right): \delta=-81.0$ (s) ppm. HRMS (APCl): $\mathrm{m} / z$ calcd. for $\mathrm{C}_{56} \mathrm{H}_{45} \mathrm{~S}_{4} \mathrm{Sn}_{2}[\mathrm{M}+\mathrm{H}]^{+}$ 1087.06117, found 1087.05980. IR (ATR): $v=3073(w), 2930$ $(w), 2899(w), 1488(w), 1479(w), 1428(w), 1250(w), 1072(w)$, $996(w), 782(\mathrm{~m}), 724(\mathrm{~m}), 694(\mathrm{~s}) \mathrm{cm}^{-1}$.

\section{References}

1. K. Müllen and G. Wegner, Electronic Materials: The Oligomer Approach, Wiley-VCH, Weinheim, 1998.

2. I. F. Perepichka and D. F. Perepichka, Handbook of Thiophene-Based Materials: Applications in Organic Electronics and Photonics, John Wiley \& Sons, Ltd, Chichester, 2009.

3. S. Scholz, D. Kondakov, B. Lussem and K. Leo, Chem. Rev., 2015, 115, 8449-8503.

4. M. P. Duffy, P.-A. Bouit, B. Geffroy, D. Tondelier and M. Hissler, Phosphorus, Sulfur, and Silicon and the Related Elements, 2014, 190, 845-853.

5. M. P. Duffy, P.-A. Bouit and M. Hissler, in Main Group Strategies towards Functional Hybrid Materials, eds. T. Baumgartner and F. Jäkle, John Wiley \& Sons Ltd, Hoboken, Chichester, 2018, ch. 12, pp. 295-327.

6. M. P. Duffy, W. Delaunay, P. A. Bouit and M. Hissler, Chem. Soc. Rev., 2016, 45, 5296-5310.

7. J. Chen and Y. Cao, Macromol. Rapid Commun., 2007, 28, 1714-1742.

8. Y. Cai, A. Qin and B. Z. Tang, J. Mater. Chem. C, 2017, 5, 7375-7389.

9. M. Shimizu, in Main Group Strategies towards Functional Hybrid Materials, eds. T. Baumgartner and F. Jäkle, John Wiley \& Sons Ltd., Hoboken, Chichester, 2018, ch. 7, pp. 163-195.

10. C.-W. So, D. Watanabe, A. Wakamiya and S. Yamaguchi, Organometallics, 2008, 27, 3496-3501.

11. H. Braunschweig, I. Fernandez, G. Frenking and T. Kupfer, Angew. Chem. Int. Ed. Engl., 2008, 47, 1951-1954.

12. I. Nagao, M. Shimizu and T. Hiyama, Angew. Chem. Int. Ed., 2009, 48, 7573-7576.

13. S. Yamaguchi, Y. Itami and K. Tamao, Organometallics, $1998,17,4910-4916$.

14. I.-M. Ramirez y Medina, M. Rohdenburg, E. Lork and A. Staubitz, Chem. Commun., 2020, 56, 9775-9778.

15. K. Jorner, R. Emanuelsson, C. Dahlstrand, H. Tong, A. V. Denisova and H. Ottosson, Chem. Eur. J., 2014, 20, 92959303.

16. H. Ottosson, Nat Chem, 2012, 4, 969-971.

17. S. Urrego-Riveros, Y. M. I. M. Ramirez, J. Hoffmann, A. Heitmann and A. Staubitz, Chemistry, 2018, 24, 5680-5696.

18. J. Linshoeft, E. J. Baum, A. Hussain, P. J. Gates, C. Nather and A. Staubitz, Angew. Chem. Int. Ed., 2014, 53, 1291612920.

19. Y. Matsumura, M. Sugihara, S. E. Tan, T. Sato, K. Hayashi, H. Nishiyama, W. M. Zhou, S. Inagi and I. Tomita, Macromol. Rapid Commun., 2019, 40, e1800929.

20. Y. M. I. M. Ramirez, M. Rohdenburg, F. Mostaghimi, S. Grabowsky, P. Swiderek, J. Beckmann, J. Hoffmann, V. Dorcet, M. Hissler and A. Staubitz, Inorg. Chem., 2018, 57, 12562-12575. 
21. S. Cosnier and A. Karyakin, Electropolymerization: Concepts, Materials and Applications, Wiley-VCH, Weinheim, 1st edn., 2010.

22. M. D. Imisides, R. John, P. J. Riley and G. G. Wallace, Electroanalysis, 1991, 3, 879-889.

23. C. Hay, C. Fischmeister, M. Hissler, L. Toupet and R. Réau, Angew. Chem. Int. Ed., 2000, 39, 1812-1815.

24. V. Lemau de Talance, M. Hissler, L. Z. Zhang, T. Karpati, L. Nyulaszi, D. Caras-Quintero, P. Bauerle and R. Reau, Chem. Commun., 2008, 2200-2202.

25. P. Yadav, S. Singhal and A. Patra, Synth. Met., 2020, 260, 116264.

26. I. Nagao, M. Shimizu and T. Hiyama, Angew. Chem. Int. Ed., 2009, 121, 7709-7712.

27. S. Urrego-Riveros, Y. M. I. M. Ramirez, D. Duvinage, E. Lork, F. D. Sönnichsen and A. Staubitz, Chem. Eur. J., 2019, 25, 13318-13328.

$28 . \quad J$. Linshoeft, Synlett, 2014, 25, 2671-2672.

29. M. C. Suh, B. Jiang and T. D. Tilley, Angew. Chem. Int. Ed., 2000, 39, 2870-2873.

30. R. S. Becker, J. Seixas de Melo, A. L. Maçanita and F. Elisei, J. Phys. Chem., 1996, 100, 18683-18695.

31. M. Bockmann, T. Schemme, D. H. de Jong, C. Denz, A. Heuer and N. L. Doltsinis, Phys. Chem. Chem. Phys., 2015, 17, 28616-28625.

32. H. Meier, U. Stalmach and H. Kolshorn, Acta Polym., 1997, 48, 379-384.

33. D. Fichou, G. Horowitz, B. Xu and F. Garnier, Synth. Met., 1990, 39, 243-259.

34. J. L. Bredas, R. Silbey, D. S. Boudreaux and R. R. Chance, J. Am. Chem. Soc., 1983, 105, 6555-6559.

35. Philippe Blanchard, A. Cravino and E. Levillain, in Handbook of Thiophene-Based Materials: Applications in Organic Electronics and Photonics, eds. I. F. Perepichka and D. F. Perepichka, John Wiley \& Sons, Ltd, Chichester, 2009.

36. G. He, W. Torres Delgado, D. J. Schatz, C. Merten, A. Mohammadpour, L. Mayr, M. J. Ferguson, R. McDonald, A. Brown, K. Shankar and E. Rivard, Angew. Chem. Int. Ed. Engl., 2014, 53, 4587-4591. 